\title{
Cytomegalovirus reactivation in a critically ill patient: a case report
}

Demet Demirkol ${ }^{1,2^{*}}$, Umay Kavgacl ${ }^{3}$, Burcu Babaoğlư ${ }^{3}$, Serhan Tanju ${ }^{4}$, Banu Oflaz Sözmen ${ }^{5}$ and Suda Tekin ${ }^{6}$

\begin{abstract}
Background: The aim of this case report is to discuss diagnostic workup and clinical management of cytomegalovirus reactivation in a critically ill immunocompetent pediatric patient.

Case presentation: A 2-year-old white boy who had no medical history presented with respiratory distress and fever. His Pediatric Risk of Mortality and Pediatric Logistic Organ Dysfunction scores were 20 and 11, respectively. Our preliminary diagnosis was multiple organ dysfunction secondary to sepsis. Antibiotic treatment was started; he was intubated and artificially ventilated. Norepinephrine infusion was started. Hemophagocytic lymphohistiocytosis was diagnosed because our patient had elevated levels of serum ferritin, bicytopenia, splenomegaly, fever $\left(>38.5^{\circ} \mathrm{C}\right)$, and hemophagocytosis shown in a bone marrow sample. Therapeutic plasma exchange and intravenously administered high-dose corticosteroid for hemophagocytic lymphohistiocytosis and continuous renal replacement treatment for acute renal failure were initiated. Following 5-day high-dose corticosteroid administration, therapeutic plasma exchange, and continuous renal replacement treatment, his clinical status and kidney and liver functions improved, and vasoactive requirement and ferritin levels decreased. He was extubated on the seventh day. On the tenth day of hospitalization he had a seizure and was diagnosed as having septic encephalopathy. His immune functions were found to be normal. Although his medical condition improved continuously, he had left spontaneous pneumothorax on the 21st day of admission as a complication of necrotizing pneumonia. Since pneumothorax persisted, left upper lobectomy surgery was performed on the 30th day of hospitalization. In the pathological examination of the excised lung tissue, features of cytomegalovirus infection were observed. Ganciclovir treatment was started. Serological tests indicated that our patient had cytomegalovirus reactivation. Antiviral treatment was stopped after 17 days, when cytomegalovirus deoxyribonucleic acid (DNA) polymerase chain reaction results became negative. He fully recovered and was discharged on the 50th day of admission.
\end{abstract}

Conclusions: Cytomegalovirus reactivation in critically ill patients is a prevalent problem and shown to be associated with higher mortality and morbidity. In a case of serologic detection of cytomegalovirus reactivation without any clinical sign of infection, pre-emptive treatment could be considered with assessment of risks and benefits for each patient. Antiviral therapy is highly recommended for patients who have risk factors identified.

Keywords: CMV reactivation, Critically ill, Pediatric, Hemophagocytic lymphohistiocytosis, Sepsis, Multiple organ dysfunction

\footnotetext{
* Correspondence: ddemirkol@ku.edu.tr

${ }^{1}$ Istanbul University Istanbul Faculty of Medicine, Department of Pediatrics,

Division of Pediatric Intensive Care, Istanbul, Turkey

${ }^{2}$ Koç University School of Medicine, Department of Pediatrics, Division of

Pediatric Intensive Care, Istanbul, Turkey

Full list of author information is available at the end of the article
}

(c) The Author(s). 2018 Open Access This article is distributed under the terms of the Creative Commons Attribution 4.0 International License (http://creativecommons.org/licenses/by/4.0/), which permits unrestricted use, distribution, and reproduction in any medium, provided you give appropriate credit to the original author(s) and the source, provide a link to the Creative Commons license, and indicate if changes were made. The Creative Commons Public Domain Dedication waiver (http://creativecommons.org/publicdomain/zero/1.0/) applies to the data made available in this article, unless otherwise stated. 


\section{Background}

Cytomegalovirus (CMV) is one of the most prevalent viral pathogens, seropositivity ranging from 50 to $90 \%$ in immunocompetent individuals $[1,2]$. Most primary CMV infections occur in the first decade of life presenting with nonspecific or subclinical symptoms and frequently resolve spontaneously. However, CMV can remain dormant in macrophages and monocytes, only to be reactivated when host immunity is compromised [3]. CMV reactivation in immunocompromised hosts is a well-known and studied problem as it leads to significant mortality and morbidity [4-6]. However, recent publications show that $\mathrm{CMV}$ reactivation in critically ill but previously immunocompetent hosts is also significantly prevalent, with an incidence as high as 15 to $20 \%$, and could be associated to the clinical outcome of these patients [2, 7-9].

Conditions such as severe sepsis, extensive burns, multiorgan failure, and long-term use of corticosteroids might lead to a secondary immune deficiency, providing suitable host factors for CMV reactivation $[3,10]$. These conditions may also give rise to acquired hemophagocytic lymphohistiocytosis (HLH), a disease that is characterized by abnormal cytokine production and excessive inflammation [11, 12]. Since HLH mimics many other conditions such as systemic infections, metabolic diseases, malignancies, and immunodeficiency, diagnosis is not easily established in clinical practice [13, 14]. An increased ferritin level above $500 \mathrm{ng} / \mathrm{mL}$ is seen in most cases, making it the first alarming finding that is suggestive of HLH. Current diagnostic criteria for HLH include: fever; splenomegaly; cytopenias; ferritin levels greater than $500 \mathrm{ng} / \mathrm{mL}$; hypofibrinogenemia (<150 mg/100 ml); and/or hypertriglyceridemia (fasting, > $265 \mathrm{mg} / 100 \mathrm{ml}$ ); low or absent natural killer (NK) cell activity; hemophagocytosis shown in bone marrow, spleen, or lymph nodes; and soluble interleukin-2 (IL-2) receptor (soluble CD25) levels greater than $2400 \mathrm{U} / \mathrm{ml}$. Five out of these eight criteria is sufficient for HLH diagnosis [15-17]. HLH itself is also an immunosuppressive condition therefore it may result in various opportunistic infections and reactivation of dormant pathogens. CMV reactivation as a consequence of this acquired immunocompromised state could occur in patients with HLH. In this case report we describe a pediatric patient who had CMV reactivation after acquired HLH and our considerations regarding diagnostic workup and clinical management. To the best of our knowledge, this is the first report with sepsis, multiple organ failure, acquired $\mathrm{HLH}$, and septic encephalopathy followed by CMV reactivation. The aim is to review the management of patients with CMV reactivation; the data for which are very limited and inconclusive.

\section{Case presentation}

A 2-year-old white boy who had no medical history presented to University Hospital Emergency Department with respiratory distress and fever. $\mathrm{He}$ is the second child of a Turkish father and a 40-year-old Uzbek mother; his older sister has no health issues. He was born at term weighing $3350 \mathrm{~g}$. Milestones were reached at the appropriate age.

On admission to the primary hospital, he had jaundice and confusion; his blood tests showed anemia, thrombocytopenia, and liver and kidney dysfunction. Suspecting malignancy, abdomen and thorax computed tomography (CT) and cranial magnetic resonance imaging (MRI) were obtained, which revealed bilateral pleural effusions with more severe parenchymal compression on his left lung. Periportal edema and hepatomegaly were detected in the abdominal CT. The cranial MRI was normal. On the day of admission, he was transferred to our pediatric intensive care unit (ICU).

At the time of admission, a physical examination revealed a confused boy (Glasgow Coma Scale was 13) with a length in 90th percentile and weight in 90th percentile. He had generalized edema and icterus. His pulse rate was 132 beats per minute (bpm), respiratory rate was 45 breaths per minute, blood pressure was 120/54 mmHg, and temperature was $35{ }^{\circ} \mathrm{C}$. Respiratory sounds were attenuated in his left lung. His abdomen was distended; his liver was palpable 4 to $5 \mathrm{~cm}$ below ribs. His Pediatric Risk of Mortality and Pediatric Logistic Organ Dysfunction scores were 20 and 11, respectively. Our preliminary diagnosis was multiple organ dysfunction secondary to sepsis. Antibiotic treatments were started with vancomycin (60 mg/kg per day) and meropenem (120 mg/kg per day) after sampling of pleural effusion, which showed characteristics of empyema (Table 1). The cultures (urine, blood, catheter, and pleural fluid) were sterile. Due to increasing respiratory distress, he was intubated and artificially ventilated. A norepinephrine infusion was started to maintain cardiac output and prevent hypotension. HLH was diagnosed since he had elevated levels of serum ferritin, bicytopenia, splenomegaly, fever $\left(>38.5{ }^{\circ} \mathrm{C}\right)$, and hemophagocytosis shown in bone marrow sample, fulfilling five out of eight diagnostic criteria for acquired HLH. He had

Table 1 Pleural effusion sampling results

\begin{tabular}{ll}
\hline Quality & Turbid \\
\hline Pleural glucose level $(\mathrm{mg} / \mathrm{dL})$ & 16 \\
Serum glucose level $(\mathrm{mg} / \mathrm{dL})$ & 62 \\
Pleural protein level $(\mathrm{g} / \mathrm{dL})$ & 3.89 \\
Serum protein level $(\mathrm{g} / \mathrm{dL})$ & 3.96 \\
Pleural lactate dehydrogenase level (U/L) & 15,172 \\
Serum lactate dehydrogenase level (U/L) & 4503 \\
Pleural leukocyte count $\left(/ \mathrm{mm}^{3}\right)$ & 13,750 \\
\hline
\end{tabular}


Table 2 Initial laboratory workup

\begin{tabular}{|c|c|c|}
\hline & Patient's result & Reference ranges \\
\hline \multicolumn{3}{|l|}{ Hemogram } \\
\hline Leukocyte count $\left(/ \mathrm{mm}^{3}\right)$ & 7000 & $5500-15,500$ \\
\hline Hemoglobin level (g/dL) & 6 & $11.5-15.5$ \\
\hline Platelet count $\left(/ \mathrm{mm}^{3}\right)$ & 22,000 & $150,000-400,000$ \\
\hline \multicolumn{3}{|l|}{ Coagulation parameters } \\
\hline aPTT (seconds) & 64 & $25-35$ \\
\hline PT (seconds) & 10 & $11-15$ \\
\hline Fibrinogen ( $g / L)$ & 7.11 & $1.25-3.0$ \\
\hline \multicolumn{3}{|l|}{ Biochemistry panel } \\
\hline Creatinine (mg/dL) & 1.98 & $0.5-1.0$ \\
\hline Uric acid (mg/dL) & 9.8 & $2.2-6.6$ \\
\hline $\mathrm{BUN}(\mathrm{mg} / \mathrm{dL})$ & 72 & $5-18$ \\
\hline Ammonia $(\mu \mathrm{mol} / \mathrm{L})$ & 26 & $17-68$ \\
\hline Alanine aminotransferase $(\mathrm{U} / \mathrm{L})$ & 65 & $5-45$ \\
\hline Aspartate aminotransferase $(\mathrm{U} / \mathrm{L})$ & 440 & $15-55$ \\
\hline Alkaline phosphatase $(U / L)$ & 116 & $130-560$ \\
\hline Gamma-glutamyl transferase (U/L) & 13 & $5-24$ \\
\hline Triglycerides (mg/dL) & 132 & $31-108$ \\
\hline Total protein (g/dL) & 3.96 & $6.1-7.9$ \\
\hline Albumin (mg/dL) & 2.1 & $3.9-5.0$ \\
\hline Direct bilirubin (mg/dL) & 19.6 & $<0.2$ \\
\hline Total bilirubin (mg/dL) & 19.9 & $0.3-1.2$ \\
\hline C-reactive protein (mg/L) & 322 & $0-5$ \\
\hline Procalcitonin $(\mu \mathrm{cg} / \mathrm{L})$ & $>100$ & $0-1$ \\
\hline Lactate dehydrogenase (U/L) & 4503 & $120-330$ \\
\hline Ferritin $(\mathrm{ng} / \mathrm{mL})$ & 10,699 & $7-140$ \\
\hline Haptoglobin (mg/dL) & 22 & $26-185$ \\
\hline
\end{tabular}

aPTT activated partial thromboplastin time, BUN blood urea nitrogen, $P T$ prothrombin time

no urinary output for the last 72 hours; his blood urea nitrogen, uric acid, and creatinine levels were increased. Initial laboratory results are shown in Table 2. Therapeutic plasma exchange (TPE) and intravenously administered high-dose corticosteroid for HLH and continuous renal replacement treatment (CRRT) for acute renal failure were initiated.

Following 5-day high-dose corticosteroid administration, TPE, and CRRT, his clinical status and kidney and liver functions improved, and his vasoactive requirement and ferritin levels decreased. The norepinephrine infusion was decreased gradually and stopped after 4 days. He was extubated on the seventh day. On the tenth day of hospitalization he had a seizure; electroencephalography, MRI, and lumbar puncture did not reveal pathological findings. Since we excluded other pathologies that may cause seizures, he was thought to have septic encephalopathy. Antiepileptic medication was started, and he did not have a seizure in the follow-up period. CRRT was continued intermittently, and completely stopped on the 14th day of hospitalization. The antibiotic treatments were stopped on the 14th day of treatment. His immune functions were also investigated; his lymphocyte subset panel and immunoglobulin levels were found to be normal (Table 3). The result of serologic testing for human immunodeficiency virus was negative.

Although his medical condition improved continuously, he had left spontaneous pneumothorax on the 21st day of admission as a complication of necrotizing pneumonia. Necrotizing pneumonia was diagnosed by thorax CT findings (Fig. 1). Since pneumothorax persisted, left upper lobectomy surgery was performed on the 30th day of hospitalization. In the pathological examination of the excised lung tissue, features of CMV infection were observed and ganciclovir $(10 \mathrm{mg} / \mathrm{kg}$ per day) treatment was started 2 days after surgery. In order to confirm the presence of CMV infection, CMV deoxyribonucleic acid (DNA) polymerase chain reaction (PCR), CMV DNA IgG avidity index, and CMV IgG and IgM tests were utilized. CMV IgM was found to be negative; however, CMV IgG was positive with high CMV DNA IgG avidity index (0.88; Table 4). These results indicated that he had CMV reactivation, rather than an acute primary CMV infection. We determined the duration of ganciclovir treatment according to the level of CMV DNA PCR (10300 copies $/ \mathrm{mL})$ in the blood. Antiviral treatment was stopped after 17 days, when CMV DNA PCR results became negative. He fully recovered and was discharged from our hospital on the 50th day of admission. He had no health problem after discharge at 6-month follow-up at an out-patient clinic.

\section{Discussion}

This case was challenging in many aspects such as having multiple serious diseases including empyema, sepsis, multiple organ failure, acquired $\mathrm{HLH}$, and septic

Table 3 Immunological function tests

\begin{tabular}{|c|c|c|}
\hline & Patient's results & Reference range \\
\hline \multicolumn{3}{|l|}{ Immunoglobulin levels } \\
\hline $\operatorname{lgM}$, serum (mg/dL) & 30 & $41-164$ \\
\hline $\lg A$, serum (mg/dL) & 68 & $14-122$ \\
\hline IgE, total (IU/mL) & 10 & $<60$ \\
\hline lgG, serum (mg/dL) & 868 & $331-1164$ \\
\hline \multicolumn{3}{|l|}{ Lymphocyte subset panel } \\
\hline CD4+ lymphocyte (\%) & 43.3 & $23-48$ \\
\hline CD4+ lymphocyte count $(/ \mu \mathrm{L})$ & 1115.74 & $500-2400$ \\
\hline CD8+ lymphocyte (\%) & 30.06 & $14-33$ \\
\hline CD8+ lymphocyte count $(/ \mu \mathrm{L})$ & 788.49 & $300-1600$ \\
\hline CD 56+ cell (\%) & 12 & $4-23$ \\
\hline
\end{tabular}

Ig immunoglobulin, $C D$ cell differentiation 
Table 4 The patient's cytomegalovirus serology

\begin{tabular}{llll}
\hline Serologic marker & Day 1 & Day 35 & Day 49 \\
\hline Cytomegalovirus IgG antibody (aU/mL) & - & 85 (positive) & - \\
Cytomegalovirus IgG avidity & - & 0.88 (index) & - \\
Cytomegalovirus IgM antibody & 0.04 (negative) & 0.41 (negative) & - \\
Cytomegalovirus DNA (PCR) & - & Positive & Negative \\
Cytomegalovirus concentration (copy/mL) & - & 11306 & - \\
\hline
\end{tabular}

CMV cytomegalovirus, $P C R$ polymerase chain reaction, DNA deoxyribonucleic acid, $l g$ immunoglobulin

encephalopathy followed by CMV reactivation. The pathogen microorganism for lung infection leading to empyema was never identified, most probably because our patient had started antibiotic treatment days ago. At the time of admission he had renal, hepatic, respiratory, cardiac, and hematological dysfunction. Despite involvement of five or more organs, which is a negative prognostic factor in multiorgan failure cases, he recovered rather quickly after acquired HLH was controlled and organ functions were supported with TPE, high-dose steroid treatment, and CRRT.

An increased ferritin level in blood is strongly associated to $\mathrm{HLH}$, and it may have a prognostic value regarding clinical outcome of the patient. A higher maximum ferritin level in the first 3 weeks of disease is found to be associated with higher mortality rates. Furthermore, the rate of decline of ferritin in response to treatment has also proved to be significant, as higher rate of decline ( $\geq 96 \%$ decrease) indicates a better prognosis than lower rate of decline $(<50 \%$ decrease) $[18,19]$. After 5-day TPE and high-dose corticosteroid treatment, our patient's ferritin levels decreased from $10,699 \mathrm{ng} / \mathrm{mL}$ to $1356 \mathrm{ng} / \mathrm{mL}$ (88\% decrease) putting him into the average prognosis group.

Several studies claimed that CMV reactivation in previously immunocompetent critically ill patients causes a remarkable increase in overall mortality, duration of hospitalization, need for mechanical ventilation, and frequency of nosocomial infections [2, 20, 21]. Definite mechanisms for these negative effects are yet to be found,

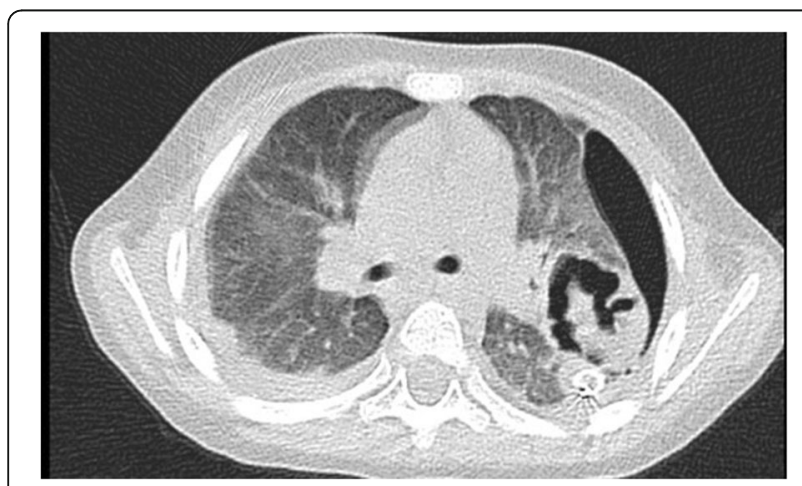

Fig. 1 Axial computed tomography image of the patient before operation current hypotheses being inactivation of host's immune defenses by CMV and cytopathic response caused by the overactive immune system [22]. Some researchers argued that CMV reactivation in critically ill patients could be merely an indicator of the patients' poor clinical status rather than causing additional morbidity and mortality by its own effects [8]. However, meta-analyses indicated that when all the data are pooled together, CMV reactivation significantly affects patient outcome and increases mortality rates by up to $81 \%$ [20]. Current evidence demonstrates that CMV reactivation should be taken seriously, but still there is no consensus among medical professionals regarding the management of these patients. There is anecdotal data that showed timely initiation of TPE contributed to recovery from severe CMV infection [23]. In addition, clinical studies on CMV reactivation in critically ill previously immunocompetent patients are all conducted in adult populations and, as a result, the significance of CMV reactivation in the pediatric population with the same characteristics is not identified yet.

In our case, ganciclovir treatment was started as soon as pathological examination of the lung specimen revealed CMV infection. When we started antiviral treatment, CMV PCR DNA and CMV immunoglobulin (Ig)G and IgM levels were not reported yet, therefore differentiating primary infection from reactivation was not possible. Later, we concluded that our case had CMV reactivation, because CMV IgG avidity index was high (0.88) while CMV IgM antibody concentration was very low, and decided to continue antiviral treatment until CMV DNA PCR became negative.

There is no definitive management guideline on CMV reactivation in critically ill patients and for each individual case, the decision whether to start antiviral treatment or not, when to stop the treatment, and how appropriate dosing should be, is left to clinicians. Initiating ganciclovir treatment to all CMV seropositive patients (prophylaxis) was suggested in a couple of papers and it could potentially prevent CMV reactivation in critically ill patients. However, this approach would be far from ideal as ganciclovir has adverse effects like decreased creatinine clearance, anemia, thrombocytopenia, and neutropenia and may not be tolerable for every ICU patient, especially those with kidney dysfunction and hematological 
problems [24, 25]. Narrowing down the target patient group for prophylactic ganciclovir treatment could be achieved by testing every ICU patient for CMV seropositivity at admission. In cases of serologic detection of CMV reactivation without any clinical sign of infection, preemptive treatment could be considered with assessment of risks and benefits for each patient. Most authors advocated use of curative antiviral therapy in cases with proven CMV reactivation (PCR and/or serology) and presence of clinical signs of infection. Antiviral therapy, such as a regimen of ganciclovir $5 \mathrm{mg} / \mathrm{kg}$ per day for at least 2 weeks [22], is highly recommended for patients with primary lung infiltrates, impaired gas exchange, and a very high viral load $(>10,000 / \mathrm{mL})$ concurrent with at least two risk factors such as: leukopenia, hemophagocytosis, absence of bacterial agent in cultures, mechanical ventilation duration of more than 2 weeks, increase in liver transaminase levels by 1.5 -fold to threefold, and increase in bilirubin levels by 1.5 -fold to threefold.

CMV reactivation in critically ill patients is a prevalent problem and shown to be associated with higher mortality and morbidity in numerous studies including metaanalyses. However, data regarding methods to accurately identify CMV reactivation, how to manage patients with CMV reactivation, and which patients should be treated, remain very limited and inconclusive. The prevalence of CMV reactivation in pediatric ICUs is not studied yet, and there is no current evidence that shows CMV reactivation affects children in the same manner as adults. Further research should be conducted to establish appropriate management guidelines for these patients.

\section{Conclusions}

CMV reactivation in critically ill patients is a prevalent problem and shown to be associated with higher mortality and morbidity. In a case of serologic detection of CMV reactivation without any clinical sign of infection, preemptive treatment could be considered with assessment of risks and benefits for each patient. Antiviral therapy is highly recommended for patients who have risk factors identified.

\footnotetext{
Availability of Data and Materials

The authors are ready to share reproducible materials described in the manuscript, including new software, databases, and all relevant raw data, freely available to any scientist wishing to use them, without breaching participant confidentially.

The authors confirm that all relevant data are included in the article and/or its supplementary information files.
}

\section{Authors' contributions}

DD is the guarantor of integrity of the entire case. DD declares that she participated in case design, definition of intellectual content, data collection, literature research, manuscript preparation, and editing and review. UK declares that he participated in case design, definition of intellectual content, manuscript preparation, and editing and review. BB declares that he participated in case design, definition of intellectual content, manuscript preparation, and editing and review. ST declares that he participated in case design, definition of intellectual content, manuscript preparation, and editing and review. BOS declares that he participated in case design, definition of intellectual content, manuscript preparation, and editing and review. ST declares that he participated in case design, definition of intellectual content, manuscript preparation, and editing and review. All authors read and approved the final manuscript.

\section{Consent for publication}

Written informed consent was obtained from the patient's legal guardians for publication of this case report and any accompanying images. A copy of the written consent is available for review by the Editor-in-Chief of this journal.

\section{Competing interests}

The authors declare that they have no competing interests.

\section{Publisher's Note}

Springer Nature remains neutral with regard to jurisdictional claims in published maps and institutional affiliations.

\section{Author details}

${ }^{1}$ Istanbul University Istanbul Faculty of Medicine, Department of Pediatrics, Division of Pediatric Intensive Care, Istanbul, Turkey. ${ }^{2}$ Koç University School of Medicine, Department of Pediatrics, Division of Pediatric Intensive Care, Istanbul, Turkey. ${ }^{3}$ Koç University School of Medicine, Istanbul, Turkey. ${ }^{4}$ Koç University School of Medicine, Department of Thoracic Surgery, Istanbul, Turkey. ${ }^{5}$ Koç University School of Medicine, Department of Pediatrics, Division of Pediatric Hematology and Oncology, Istanbul, Turkey. ${ }^{6}$ Koç University School of Medicine, Department of Infectious Diseases, Istanbul, Turkey.

Received: 16 September 2017 Accepted: 7 April 2018

Published online: 11 June 2018

References

1. Cannon MJ, Schmid DS, Hyde TB. Review of cytomegalovirus seroprevalence and demographic characteristics associated with infection. Rev Med Virol. 2010;20:202-13.

2. Limaye AP, Boeckh M. Cytomegalovirus (CMV) in critically-ill patients: pathogen or bystander? Rev Med Virol. 2010;20:372-9.

3. Kondo K, Kaneshima H, Mocarski ES. Human cytomegalovirus latent infection of granulocyte-macrophage progenitors. Proc Natl Acad Sci U S A. 1994;91:11879-83.

4. Kusne S, Shapiro R, Fung J. Prevention and treatment of cytomegalovirus infection in organ transplant recipients. Transpl Infect Dis. 1999;1:187-203.

5. Razonable RR, Brown RA, Espy MJ, Rivero A, Kremers W, Wilson J, Groettum C, Smith TF, Paya CV. Comparative quantitation of cytomegalovirus (CMV) DNA in solid organ transplant recipients with $\mathrm{cmv}$ infection by using two high-throughput automated systems. J Clin Microbiol. 2001;39:4472-6.

6. Wohl DA, Zeng D, Stewart P, Glomb N, Alcorn T, Jones S, Handy J, Fiscus S, Weinberg A, Gowda D, et al. Cytomegalovirus viremia, mortality, and endorgan disease among patients with aids receiving potent antiretroviral therapies. JAIDS. 2005;38:538-44.

7. Limaye AP, Kirby KA, Rubenfeld GD, Leisenring WM, Bulger EM, Neff MJ, Gibran NS, Huang M-L, Santo TK, Corey L, et al. Cytomegalovirus reactivation in critically-ill immunocompetent patients. JAMA. 2008;300:413-22.

8. Heininger A, Haeberle H, Fischer I, Beck R, Riessen R, Rohde F, Meisner C, Jahn G, Koenigsrainer A, Unertl $K$, et al. Cytomegalovirus reactivation and associated outcome of critically ill patients with severe sepsis. Crit Care. 2011;15:R77

9. Al-Omari A, Aljamaan F, Alhazzani W, Salih S, Arabi Y. Cytomegalovirus infection in immunocompetent critically ill adults: literature review. Ann Intensive Care. 2016;6:110.

10. Frantzeskaki FG, Karampi E-S, Kottaridi C, Alepaki M, Routsi C, Tzanela M, Vassiliadi DA, Douka E, Tsaousi S, Gennimata V, et al. Cytomegalovirus reactivation in a general, nonimmunosuppressed intensive care unit population: Incidence, risk factors, associations with organ dysfunction, and inflammatory biomarkers. J Crit Care. 2015;30:276-81.

11. Ishii E, Ohga S, Imashuku S, Yasukawa M, Tsuda H, Miura I, Yamamoto K, Horiuchi H, Takada K, Ohshima K, et al. Nationwide survey of hemophagocytic lymphohistiocytosis in Japan. Int J. Hematology. 2007;86:58. 
12. Lehmberg K, Ehl S. Diagnostic evaluation of patients with suspected haemophagocytic lymphohistiocytosis. Br J Haematol. 2013;160:275-87.

13. Sen ES, Steward CG, Ramanan AV. Diagnosing haemophagocytic syndrome. Arch Dis Child. 2017:102:279.

14. Palazzi DL, McClain KL, Kaplan SL. Hemophagocytic syndrome in children: an important diagnostic consideration in fever of unknown origin. Clin Infect Dis. 2003;36:306-12.

15. Henter J-I, Horne A, Aricó M, Egeler RM, Filipovich AH, Imashuku S, Ladisch S, McClain K, Webb D, Winiarski J, et al. HLH-2004: Diagnostic and therapeutic guidelines for hemophagocytic lymphohistiocytosis. Pediatr Blood Cancer. 2007;48:124-31.

16. Cetica V, Sieni E, Pende D, Danesino C, De Fusco C, Locatelli F, Micalizzi C, Putti MC, Biondi A, Fagioli F, et al. Genetic predisposition to hemophagocytic lymphohistiocytosis: Report on 500 patients from the Italian registry. J Allerg Clin Immunol. 2016:137:188-96.

17. Risma K, Jordan MB. Hemophagocytic lymphohistiocytosis: updates and evolving concepts. Curr Opin Ped. 2012;24:9-15.

18. Lin TF, Ferlic-Stark LL, Allen CE, Kozinetz CA, McClain KL. Rate of decline of ferritin in patients with hemophagocytic lymphohistiocytosis as a prognostic variable for mortality. Pediatr Blood Cancer. 2011;56:154-5.

19. Allen CE, Yu X, Kozinetz CA, KL MC. Highly elevated ferritin levels and the diagnosis of hemophagocytic lymphohistiocytosis. Pediatr Blood Cancer. 2008;50:1227-35.

20. Kalil AC, Florescu DF. Is cytomegalovirus reactivation increasing the mortality of patients with severe sepsis? Crit Care. 2011;15:138.

21. Osawa R, Singh N. Cytomegalovirus infection in critically ill patients: a systematic review. Crit Care. 2009;13:R68.

22. Papazian L, Hraiech S, Lehingue S, Roch A, Chiche L, Wiramus S, Forel J-M. Cytomegalovirus reactivation in ICU patients. Intensive Care Med. 2016;42:28-37.

23. Salim SA, Akula YV, Noszály BB, et al. Potential role of plasmapheresis in severe cytomegalovirus infection with ongoing immune mediated hemolysis and low complement level. J Renal Inj Prev. 2018;7:x. https://doi. org/10.15171/jip2018.xx.

24. Reischig T, Jindra P, Hes O, Svecová M, Klaboch J, Treska V. Valacyclovir prophylaxis versus preemptive valganciclovir therapy to prevent cytomegalovirus disease after renal transplantation. Am J Transplant. 2008;8:69-77.

25. Forster MR, Trgovcich J, Zimmerman P, Chang A, Miller C, Klenerman P, Cook CH. Antiviral prevention of sepsis induced cytomegalovirus reactivation in immunocompetent mice. Antivir Res. 2010;85:496-503.

\section{Ready to submit your research? Choose BMC and benefit from:}

- fast, convenient online submission

- thorough peer review by experienced researchers in your field

- rapid publication on acceptance

- support for research data, including large and complex data types

- gold Open Access which fosters wider collaboration and increased citations - maximum visibility for your research: over $100 \mathrm{M}$ website views per year 